Article

\title{
Straightforward synthesis of beta zeolite encapsulated Pt nanoparticles for the transformation of 5-hydroxymethyl furfural into 2,5-furandicarboxylic acid
}

\author{
Xiaoling Liu, Lei Chen, Hongzhong Xu, Shi Jiang, Yu Zhou *, Jun Wang \# \\ State Key Laboratory of Materials-Oriented Chemical Engineering, College of Chemical Engineering, Nanjing Tech University, Nanjing 210009, Jiangsu, \\ China
}

\section{A R T I C L E I N F O}

\section{Article history:}

Received 18 July 2020

Accepted 31 August 2020

Available online 22 November 2020

\section{Keywords:}

Hydrothermal synthesis

Zeolite

Noble metal nanoparticles

Heterogeneous catalysis

Biomass conversion

\begin{abstract}
A B S T R A C T
Encapsulating noble metal nanoparticles (NPs) within the zeolite framework enhances the stability and accessibility of active sites; however, direct synthesis remains a challenge because of the easy precipitation of noble metal species under strong alkali crystallization conditions. Herein, beta zeolite-encapsulated Pt NPs (Pt@Beta) were synthesized via a hydrothermal approach involving an unusual acid hydrolysis preaging step. The ligand-(3-mercaptopropyl)trimethoxysilane-and Pt precursor were cohydrolyzed and cocondensed with a silica source in an initially weak acidic environment to prevent colloidal precipitation by enhancing the interaction between the Pt and silica species. Thus, the resultant $0.2 \% \mathrm{Pt} @$ Beta was highly active in the transformation of 5-hydroxymethylfurfural into 2,5-furandicarboxylic acid (FDCA) under atmospheric $\mathrm{O}_{2}$ conditions by using water as the solvent while stably evincing a high yield (90\%) associated with a large turnover number of 176 . The excellent catalysis behavior is attributable to the enhanced stability that inhibits Pt leaching and strengthens the intermediates that accelerate the rate-determining step for the oxidation of 5-formyl-2-furan carboxylic acid into FDCA.
\end{abstract}

(C) 2021, Dalian Institute of Chemical Physics, Chinese Academy of Sciences. Published by Elsevier B.V. All rights reserved.

\section{Introduction}

Noble metal nanoparticles (NPs) have been attracting widespread attention in the catalytic field due to the versatility through manipulation of their size, dispersion, location, and electronic features [1-5]. Heterogeneous noble metal NPs on porous materials are preferred because of their exploitable advantages, which include facile operation, separation, and recycling [4-6]. The chemical composition, porosity, morphology, and surface state of the supports, in conjunction with the immobilization methodology, significantly contribute to the behavior of heterogeneous noble metal NPs and consequently contribute to the immensely growing enthusiasm in this area $[2,7,8]$. However, the high surface energy of noble metal NPs usually leads to a high risk of deactivation due to sintering, leaching, etc. [4,6]. Encapsulating noble metal NPs within zeolite crystals provides an alternative strategy for alleviating this problem by enhancing stability via the strengthened interaction between the zeolite skeleton and noble metal NPs in a confined space [8-11]. Conventionally, locating the noble metal

\footnotetext{
*Corresponding author. Tel/Fax: +86-25-58139803; E-mail: njutzhouyu@njtech.edu.cn

\# Corresponding author. E-mail: junwang@njtech.edu.cn

This work was supported by the National Natural Science Foundation of China (22072065, U1662107, 21476109, 21303084), Six talent peaks project in Jiangsu Province (JNHB-035), Jiangsu Provincial Science Foundation for Youths (SBK2020044703), and the Project of Priority Academic Program Development of Jiangsu Higher Education Institutions (PAPD).

DOI: 10.1016/S1872-2067(20)63720-2 | http://www.sciencedirect.com/science/journal/18722067 | Chin. J. Catal., Vol. 42, No. 6, June 2021
} 
NPs inside the microchannels of a porous material normally results in pore blockage and limited mass transfer, which are unfavorable in a heterogeneous catalysis process [4,6,11]. Nonetheless, uniform zeolite microchannels also enable the regulation of the entrance probability and diffusion rates of small molecules according to their sizes and organic groups $[8,10,11]$. This feature artistically promotes the activity and controls the selectivity, especially in a tandem reaction involving multiple intermediates [12]. However, the challenge ensues from the task-specific synthesis of aiming zeolite-encapsulated noble metal NPs [6,11-13], as well as gaining insight into the encapsulation effect in the target reaction.

The abundant biomass, as the only carbon-containing sustainable resource, is among the most promising alternatives to traditional fossil fuels and chemicals [14-20]. Robust approaches have been proposed for the catalytic conversion of biomass-based platform molecules into value-added chemicals $[15,16]$. One of these potential platform molecules is 5-hydroxymethylfurfural (HMF), which can be easily obtained from carbohydrates, representing the major component of biomass $[16,21]$. The hydrogenation or oxidation of HMF produces many valuable chemicals, and the most dramatic illustration is the 2,5-furandicarboxylic acid (FDCA), which is a potential alternative to terephthalic acid in the production of bulk polyester materials [16,20-22]. The oxidation of HMF to FDCA with molecular oxygen $\left(\mathrm{O}_{2}\right)$ over a heterogeneous catalyst is favorable because of its energy-saving and environmentally friendly nature [21,22]. Supported noble metal $\mathrm{CAu}, \mathrm{Pd}, \mathrm{Pt}, \mathrm{Ru}$, etc.) NPs are the most extensively studied heterogeneous catalysts; however, they still suffer from harsh reaction conditions (high temperature and pressure) and deactivation due to aggregation, poisoning, and leaching $[16,21]$. Nonetheless, establishing facile recyclable supported noble metal NP catalysts with high efficiency under relatively mild conditions remains a challenge.

In this work, we directly synthesized beta zeolite (BEA topology)-encapsulated Pt NPs, hereafter abbreviated as Pt@Beta, for the oxidation of HMF into FDCA. Although zeolite-supported Pt NPs have been widely investigated, they are normally prepared via the conventional postimpregnation method $[6,13]$. Several notable examples have also been reported for zeolite-encapsulated Pt NPs [8-13,23]. For example, Pt NPs were integrated into the skeleton of LTA topological zeolite via a hydrothermal route using ligand-stabilized Pt precursors [23]. A seed-directed growth technique was used to encapsulate Pt NPs within the beta framework [8]. Notwithstanding, none of them is related to the direct hydrothermal synthesis of beta-encapsulated Pt NPs. Our direct hydrothermal synthesis employed sodium hexachloroplatinate(IV)hexahydrate $\left(\mathrm{Na}_{2} \mathrm{PtCl}_{6} \cdot 6 \mathrm{H}_{2} \mathrm{O}\right)$ as the noble metal precursor and (3-mercaptopropyl)trimethoxysilane (MPTS) as the ligand. More importantly, we adopted a unique acid-cohydrolysis route favoring better metal-silica interactions, which could inhibit the precipitation of metal species in the post-alkali crystallization environment. The synthesis was optimized to enable the high crystallinity, large surface area, and in situ encapsulation of Pt NPs within the beta framework. In general, $\mathrm{Au}$ and Pd NPs are the most investigated noble metal active sites for the oxidation of HMF into FDCA $[15,16,21,24,25]$. Only a few Pt catalysts have been developed for this reaction [21], including a homogeneous efficient Pt catalyst [26]. The presently constructed Pt NPs inside the beta zeolite matrix, representatively 0.2\%Pt@Beta, exhibited a high yield with a large turnover number (TON), which was superior, or at least comparable to the previous efficient $\mathrm{Au}$ or Pd catalysts $[15,16,21,24,25]$. The enhanced stability and promoted affinity toward the key reaction intermediates arising from the encapsulation effect were found to be responsible for the outstanding catalytic behavior.

\section{Experimental}

\subsection{Synthesis}

Typically, to synthesize Pt@Beta, tetraethyl orthosilicate (TEOS, $10.6 \mathrm{~g}$ ), concentrated hydrochloric acid ( $\mathrm{HCl}, 36 \mathrm{wt} \%$, $0.4 \mathrm{~g}$ ), water (15.5 g), $\mathrm{Na}_{2} \mathrm{PtCl}_{6} \cdot 6 \mathrm{H}_{2} \mathrm{O}$, and MPTS were stirred at $90{ }^{\circ} \mathrm{C}$ for $4 \mathrm{~h}$, during which water was repeatedly added to avoid the transformation of gel into dry solid powder. Subsequently, tetraethylammonium hydroxide (TEAOH, $7.365 \mathrm{~g}$ ) and sodium aluminate $\left(\mathrm{NaAlO}_{2}, 0.512 \mathrm{~g}\right)$ were added, and the resulting gel was aged for $24 \mathrm{~h}$ at room temperature. Subsequently, the gel was transferred into a $50 \mathrm{~mL}$ Teflon-lined stainless-steel autoclave and statically crystallized at $140{ }^{\circ} \mathrm{C}$ for $14 \mathrm{~d}$. Finally, the solid was separated by filtration, washed with deionized water, and dried at $100{ }^{\circ} \mathrm{C}$ in air. The solid was calcinated at $550{ }^{\circ} \mathrm{C}$ for $5 \mathrm{~h}$ in an air stream to remove the template and then reduced at $240{ }^{\circ} \mathrm{C}$ for $4 \mathrm{~h}$ in a $10 \% \mathrm{H}_{2}$ and $90 \% \mathrm{~N}_{2}$ atmosphere. Moreover, Pt-free beta was similarly synthesized in the absence of Pt precursors and ligands. The Pt NPs were supported on beta via a traditional wet-impregnation strategy using the Pt precursor of $\mathrm{Na}_{2} \mathrm{PtCl}_{6} \cdot 6 \mathrm{H}_{2} \mathrm{O}$, thereby providing a control sample, i.e., Pt/Beta.

\subsection{Characterization}

X-ray diffraction (XRD) patterns were recorded on a Rigaku SmartLab diffractometer ( $\mathrm{Cu}$ source, $45 \mathrm{kV}, 100 \mathrm{~mA}, 5^{\circ}-50^{\circ}$ ). Transmission electron microscopy (TEM) images were obtained using a JEM-2100 (JEOL) electron microscope operating at $200 \mathrm{kV}$. High-angle annular dark-field scanning transmission electron microscopy (HAADF-STEM) images and energy-dispersive X-ray spectra (EDS-mapping) were performed on a JEM2100 plus. Field emission scanning electron microscopy (SEM) images were collected using a field emission scanning electron microscope (HITACHI S-4800). The nitrogen $\left(\mathrm{N}_{2}\right)$ sorption experiment was conducted at $77 \mathrm{~K}$ on a BELSORP-Max analyzer. Fourier-transform infrared (FT-IR) spectra were obtained on an Agilent Cary 660 instrument (4000-400 $\mathrm{cm}^{-1}$ ). The chemical compositions were analyzed via inductively coupled plasma (ICP) spectrometery (Jarrell-Ash 1100), whereas the surface chemical state was analyzed through X-ray photoelectron spectroscopy (XPS) on a Kratos AXIS Supra X-ray photoelectron spectrometer equipped with $\mathrm{Al} K_{\alpha}$ radiation. 


\subsection{Synthesis of FDCA from $H M F$}

The oxidation of HMF into FDCA was performed in a glass tube under atmospheric $\mathrm{O}_{2}$ pressure. In a typical run, $\mathrm{HMF}(0.1$ $\mathrm{mmol})$, sodium carbonate $(0.6 \mathrm{mmol})$, catalyst $(0.1 \mathrm{~g})$, and water $(4 \mathrm{~mL})$ were added successively. After charging and deflating $\mathrm{O}_{2}$ thrice, the mixture was stirred at $90{ }^{\circ} \mathrm{C}$ for a preset time. After the reaction, the mixture was diluted with water to 100 $\mathrm{mL}$. The liquid phase was collected by centrifugation and then analyzed by liquid chromatography (LC, Thermo Scientific UltiMate 3000) equipped with a UV detector and a capillary column (Arcus EP-C18 $4.6 \mathrm{~mm} \times 250 \mathrm{~mm}$ ) with an acid mobile phase of $75 \%$ water and $25 \%$ acetonitrile, flow velocity of 0.7 $\mathrm{mL} \mathrm{min}-1$, and column temperature of $25{ }^{\circ} \mathrm{C}$.

\subsection{Adsorption behavior}

The static adsorption of HMF, 5-hydroxymethyl-2-furan carboxylic acid (HMFCA), 5-formyl-2-furancarboxylic acid (FFCA), and FDCA on $0.2 \% \mathrm{Pt} @$ Beta was investigated in the absence and presence of $\mathrm{Na}_{2} \mathrm{CO}_{3}$. Typically, 0.2\%Pt@Beta (20 $\mathrm{mg}$ ), adsorbate (0.001 mmol), $\mathrm{Na}_{2} \mathrm{CO}_{3}$ ( 0 or $0.006 \mathrm{mmol}$ ), and water $(1 \mathrm{~mL})$ were stirred at room temperature for $24 \mathrm{~h}$. Subsequently, the liquid phase was isolated by filtration and analyzed by LC. The adsorbed organic compound was calculated from the variation in the adsorbate concentration before and after adsorption.

\subsection{Zeta potential}

The zeta potentials of the colloidal particles in the aqueous solution were prepared with different organic compounds in the presence or absence of $\mathrm{Na}_{2} \mathrm{CO}_{3}$. Typically, $10 \mathrm{~mL}$ of an aqueous solution of an organic compound (reactant, intermediate, or product, $1 \mathrm{mmol} \mathrm{L}-1$ ), 0.2\%Pt@Beta (20 mg), and $\mathrm{Na}_{2} \mathrm{CO}_{3}$ (0 or $0.006 \mathrm{mmol}$ ) were mixed in a $10 \mathrm{~mL}$ centrifuge tube and ultrasonically treated for $30 \mathrm{~min}$. After stewing for 1 $\mathrm{h}$, the upper solution was measured using a dynamic light scattering instrument (Malvern Instruments Zetasizer Nano ZS 90).

\section{Results and discussion}

\subsection{Fabrication of beta-encapsulated Pt nanoparticles}

Beta zeolite-encapsulated Pt NPs, named $x \%$ Pt@Beta $(x$ is the theoretical weight percentage of Pt in the gel), was synthesized according to the route shown in Scheme 1. The typical initial gel composition was $1 \mathrm{SiO}_{2}: 0.05 \mathrm{Al}_{2} \mathrm{O}_{3}: 0.35$ TEAOH:22.5 $\mathrm{H}_{2} \mathrm{O}$ :0.00067 Pt, followed by hydrothermal crystallization at $140{ }^{\circ} \mathrm{C}$ for $14 \mathrm{~d}$. Various synthetic parameters were investigated, including the addition of a Pt precursor $\left(\mathrm{Na}_{2} \mathrm{PtCl}_{6} \cdot 6 \mathrm{H}_{2} \mathrm{O}\right)$ and ligand (organosilane), as well as the amount and type of ligand. Only amorphous products were observed by adding Pt precursor after aging and before crystallization with or without MPTS, which is a common ligand for the synthesis of zeolite-encapsulated noble metal NPs (Fig. S1, entries 1 and 2, Table S1). Conversely, the beta phase formed when the Pt pre-

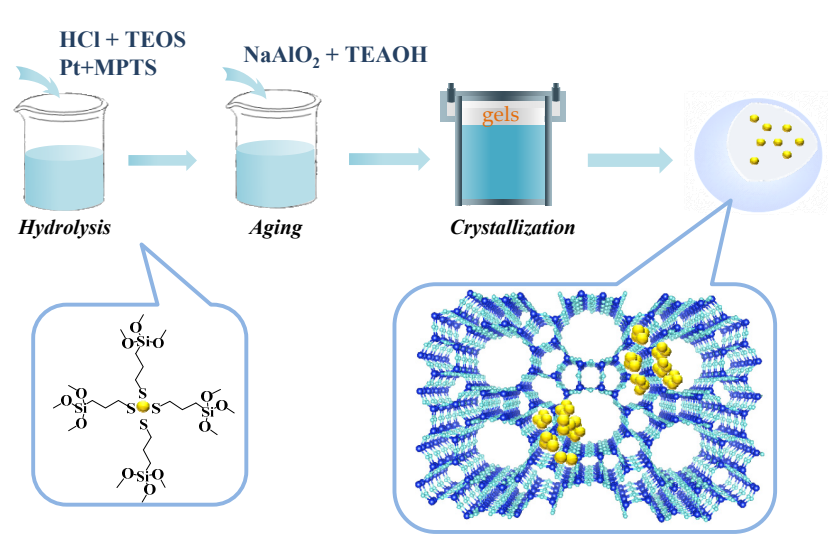

Scheme 1. Schematic diagram for the preparation of Pt@Beta.

cursor and MPTS were added in the initial acid-hydrolysis step, in the absence of MPTS, resulted in an amorphous phase (Fig. S2, entries 3 and 4, Table S1) [28]. Therefore, MPTS is indispensable for integrating Pt species into beta zeolite, which is attributable to the strengthened interaction between the silica precursor and Pt species via this ligand. On the one hand, MPTS can cohydrolyze and cocondense with TEOS under mild acidic conditions; on the other hand, it can interact with Pt species via coordination or Van der Waals forces [29,30]. Several other ligands of (3-aminopropyl)trimethoxysilane, (3-aminopropyl) triethoxysilane, and (3-chloropropyl)triethoxysilane were used in this synthesis (Fig. S3, entries 3 and 5-7, Table S1). Similar to MPTS, (3-chloropropyl)triethoxysilane could also produce Pt@Beta with strong peaks in the XRD patterns (curves c and d, Fig. S3). The higher Pt content ( 0.2 wt $\%$, identical to the theoretic content in the gel) obtained by using MPTS, compared to that $(0.16 \mathrm{wt} \%)$ attained using the chloro-tethered one (entries 3 and 7, Table S1), implies that MPTS is the more beneficial ligand for encapsulating Pt species, which is potentially attributable to the appropriate coordination capacity of -SH toward Pt species [29,30]. The survey of the MPTS amount showed that the presence of a small amount of MPTS (MPTS/Pt molar ratio: 4) led to the incorporation of Pt species, but with relatively low Pt content (0.17 wt\%) (entry 8, Table S1) and weak peaks in the XRD pattern (curve a, Fig. S4). A moderate MPTS/Pt molar ratio of 14 promoted the encapsulation of Pt species (entry 11, Table S1) and endowed a strong XRD pattern (curve d, Fig. S4), indexing high crystallinity [31-35]. In contrast, excessive MPTS with an MPTS/Pt molar ratio of 28 resulted in a consistently high Pt content of $0.2 \mathrm{wt} \%$ (entry 3, Table S1) but with weakened XRD diffraction peaks (curve e, Fig. S4). Consequently, the optimal sample, i.e., 0.2\%Pt@Beta, was obtained with the synthetic parameters in entry 11 of Table S1. For comparison, another Pt-containing beta zeolite with a higher Pt content (0.41 wt\%), termed 0.5\%Pt@Beta, was synthesized by feeding more Pt precursors into the initial acid-cohydrolysis stage with an MPTS/Pt molar ratio of 14 (entry 12, Table S1). In addition, the Pt-free neat beta sample was similarly synthesized in the absence of a Pt precursor and ligand.

The SEM images display almost the same morphology as 


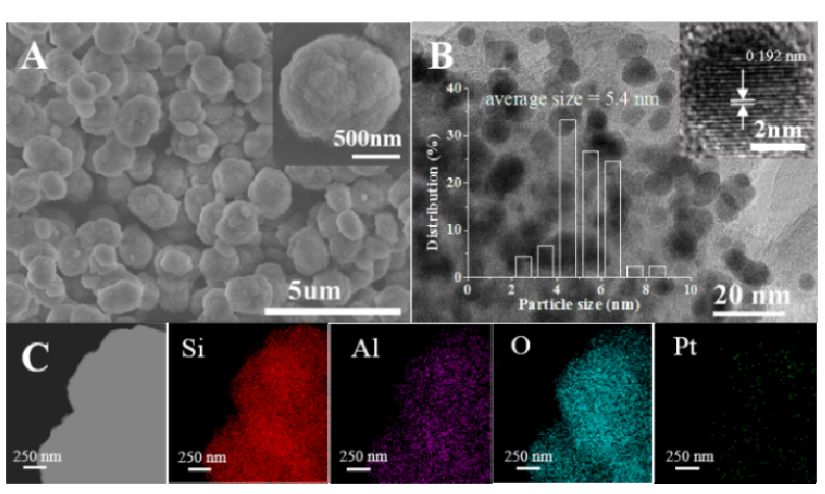

Fig. 1. SEM (A), and TEM(B) images of 0.2\%Pt@Beta; (C) HAADF-STEM and corresponding elemental mapping images for $\mathrm{Si}, \mathrm{Al}, \mathrm{O}$, and Pt elements of 0.2\%Pt@Beta.

beta, 0.2\%Pt@Beta, and 0.5\%Pt@Beta (Figs. 1(A) and S5). Their popcorn-like primary particles are tightly packed and fused to generate secondary particles, loosely packed ellipsoids with diameters of 1-2 $\mu \mathrm{m}$, and an uneven surface. The TEM images of the 0.2\%Pt@Beta (Fig. 1(B)) and 0.5\%Pt@Beta (Fig. S6) illustrated the formation of Pt NPs with average particle sizes of 5.4 and $6.5 \mathrm{~nm}$, respectively. Apparently, a lattice distance of $0.192 \mathrm{~nm}$ consisted with the [200] lattice plane, and the embedded Pt NPs within the zeolite crystals was observable in the high-resolution TEM images of the typical sample, 0.2\%Pt@Beta (Fig. S7) [36,37]. Furthermore, the HADDF-STEM images and the corresponding elemental imaging of 0.2\%Pt@Beta (Fig. 1(C)) showed a relatively homogeneous distribution of the $\mathrm{Si}, \mathrm{Al}, \mathrm{O}$, and Pt elements.

The XRD patterns of beta, 0.2\%Pt@Beta, and 0.5\%@Beta exhibited typical diffraction peaks for the BEA phase, thereby reflecting the highly crystallized zeolite framework [27,33]. No peaks were observed for the possible existence of other impurities or aggregated Pt species [37]. Figs. 2(A)-(C) show the fitting of the profile calculated for the BEA model to the experimental data (TOPAS-Academic V6.0) [38-40]. The fitted XRD patterns follow the experimental ones, and the cell parameters are summarized in Table 1. The unit cell parameters for these samples are similar to one other, as well as to those of previous BEA zeolites [38]. Nitrogen sorption experiments presented the sorption isotherms and pore size distributions in Fig. 2(D), thereby revealing the pore information. Notably, the BEA zeolite possessed the type I + IV sorption isotherms with a sharp uptake at low pressure [33-35], which was consistent with the typical microporous structure and was further demonstrated by the narrow pore size distribution focusing at $0.65 \mathrm{~nm}$. The weak uptake in the moderate relative pressure originates from the mesopore formation owing to the loose packing of the primary particles, as shown in the SEM images. Table 1 lists their surface areas of 497-515 $\mathrm{m}^{2} \mathrm{~g}^{-1}$ and pore volumes of $0.27-0.31$ $\mathrm{cm}^{3} \mathrm{~g}^{-1}$, with a similar average pore size of $2.1 \mathrm{~nm}$. The micropores and mesopores for these samples were analyzed by the $t$-plot method (Table S2) and showed a high micropore/mesopore proportion, which was consistent with a previous report [35]. This is possibly due to the low Pt content, which only slightly affects pore formation. The FT-IR spectra in Fig. 2(E) showed approximately the same characteristic adsorption bands of $0.2 \% \mathrm{Pt} @ B$ Bta and $0.5 \% @ B e t a$ relative to that of the neat beta, thereby implying the similarity of their frameworks [33].

Furthermore, XPS analysis was conducted to clarify the surface chemical states of 0.2\%Pt@Beta and 0.5\%Pt@Beta, and the outcome was compared with beta and $0.2 \% \mathrm{Pt} /$ Beta (Pt NPs
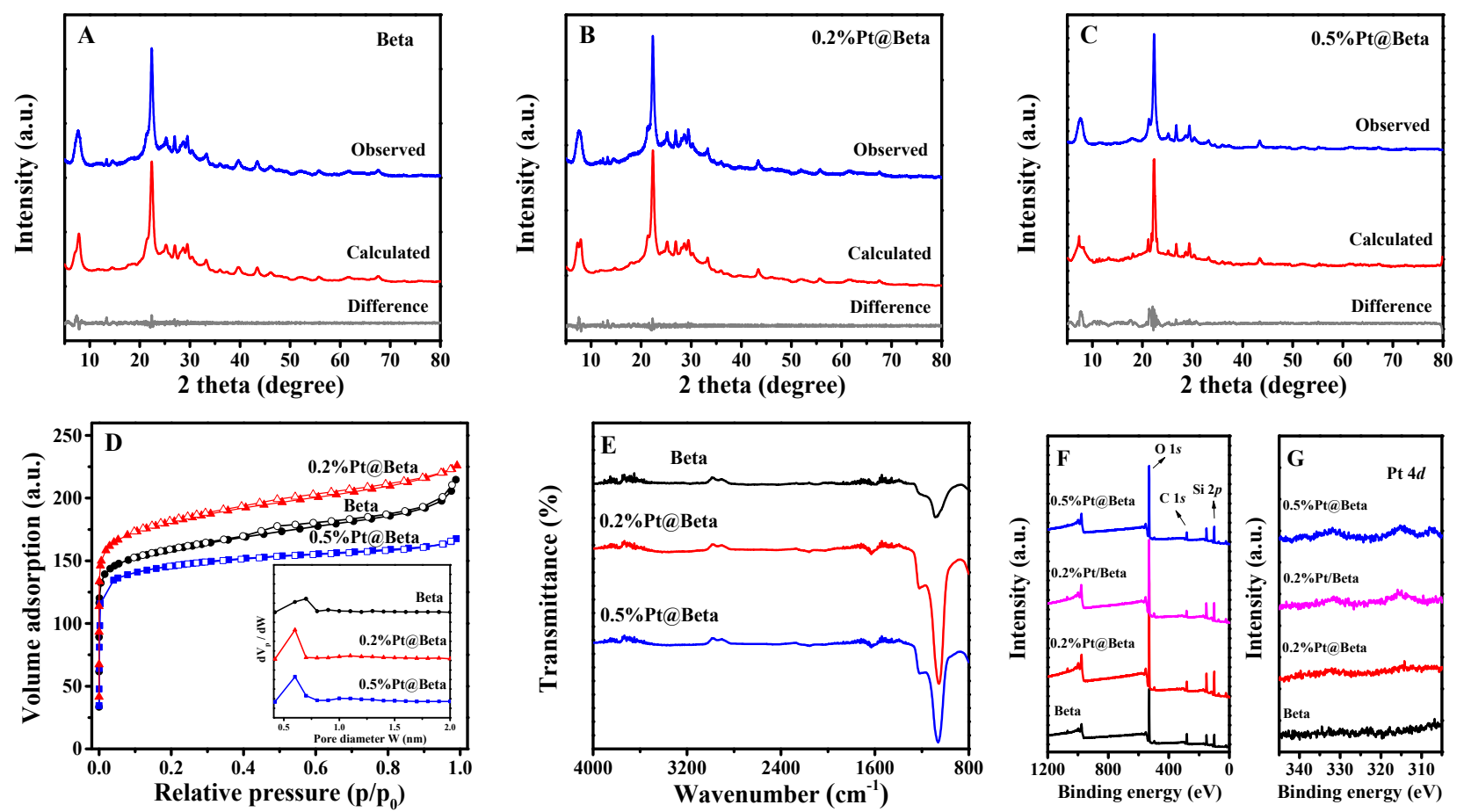

Fig. 2. (A-C) powder XRD patterns; (D) $\mathrm{N}_{2}$ sorption isotherms (the inset is the pore size dispersion curves); (E) FTIR spectra; (F) Survey scan; (G) Pt $4 d$ XPS spectra. 
Table 1

Textual properties.

\begin{tabular}{|c|c|c|c|c|c|c|c|}
\hline \multirow{2}{*}{ Sample } & \multirow{2}{*}{$S_{\text {BET }}{ }^{a}\left(m^{2} g^{-1}\right)$} & \multirow{2}{*}{$V \mathrm{p}^{\mathrm{b}}\left(\mathrm{cm}^{3} \mathrm{~g}^{-1}\right)$} & \multirow{2}{*}{$D_{\mathrm{av}} \mathrm{c}(\mathrm{nm})$} & \multirow{2}{*}{$\mathrm{Pt}^{\mathrm{d}}(\mathrm{wt} \%)$} & \multicolumn{3}{|c|}{ Unit cell parameters e $(\AA)$} \\
\hline & & & & & $\mathrm{a}$ & $\mathrm{b}$ & $\mathrm{c}$ \\
\hline Beta & 511 & 0.31 & 2.5 & 0 & 12.66 & 12.65 & 26.41 \\
\hline 0.2\%Pt@Beta & 497 & 0.28 & 2.2 & 0.20 & 12.65 & 12.56 & 26.69 \\
\hline 0.5\%Pt@Beta & 509 & 0.27 & 2.1 & 0.41 & 12.69 & 12.57 & 26.49 \\
\hline $0.2 \% \mathrm{Pt} /$ Beta & 468 & 0.25 & 2.1 & 0.20 & 12.66 & 12.66 & 26.40 \\
\hline
\end{tabular}

a BET surface area.

b Total pore volume.

cAverage pore size.

dPt content.

e Unit cell parameters were obtained using TOPAS-Academic V6.0.

loaded on Beta prepared by conventional wet impregnation, with a Pt loading of $0.2 \mathrm{wt} \%$ and average Pt size of $12 \mathrm{~nm}$ (Figs. S8-S12). In the survey scan spectra (Fig. 2(F)), all the samples exhibited signals at 284, 532, and $102 \mathrm{eV}$ for $\mathrm{C} 1 s, 01 s$, and $\mathrm{Si}$ $2 p$, respectively. In the $\mathrm{Pt} 4 d$ spectra (Fig. 2(G)), both $0.5 \% \mathrm{Pt} @ B$ Beta and $0.2 \% \mathrm{Pt} /$ Beta presented 2 peaks at 331.5 and $315.2 \mathrm{eV}$, corresponding to metallic Pt (0) species [41,42], which was, however, lacking for 0.2\%Pt@Beta. The contrast is further reflected by comparing the signals with that of Beta. These phenomena indicate that the Pt NPs were encapsulated within the crystals of the beta framework at a relatively low loading of $0.2 \mathrm{wt} \%$, such that no external superficial Pt species could be detected via XPS, while the Pt NPs outside or near the surface of the zeolite crystals appeared at the relatively high loading of $0.5 \mathrm{wt} \%$, similar to the impregnation sample, i.e., $0.2 \% \mathrm{Pt} /$ Beta. To investigate the stability of Pt NPs encapsulated by the BEA structure, the $0.2 \% \mathrm{Pt} @$ Beta sample was calcinated at $650{ }^{\circ} \mathrm{C}$ for $5 \mathrm{~h}$ in an air stream and then reduced under a $\mathrm{H}_{2} / \mathrm{N}_{2}(10 \% / 90 \%)$ atmosphere at $240{ }^{\circ} \mathrm{C}$ for $4 \mathrm{~h}$. The obtained sample was named as $0.2 \% \mathrm{Pt} @ B$ Beta-650 and measured via XPS and TEM. Similar XPS spectra and TEM images were observed for these two samples, implying satisfactory sintering resistance, which was derived from the encapsulation effect (Figs. S13 and S14).

\subsection{Oxidation of 5-hydroxymethylfural}

The above-stated catalytic performance of Pt@Beta was evaluated in the transformation of HMF into FDCA (Scheme 2) under atmospheric $\mathrm{O}_{2}$ and a relatively low temperature of $90{ }^{\circ} \mathrm{C}$ conditions using water as the solvent. The oxidation of HMF effectively proceeded over 0.2\%Pt@Beta, exhibiting near-complete conversion and selectivity, with an FDCA yield of over $99 \%$ and a TON of 97 (entry 1, Table 2). The low FDCA

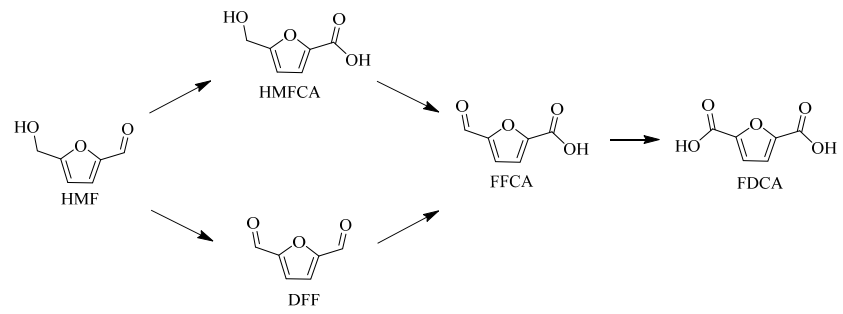

Scheme 2. Typical reaction pathways for the oxidation of HMF into FDCA in the presence and absence of the base. yield of $\sim 1.0 \%$ of neat Beta (entry 2, Table 2) revealed the catalytic active sites of the Pt NPs. In contrast, the $0.2 \% \mathrm{Pt} /$ Beta resulted in a low selectivity to produce FDCA with a yield of $37 \%$, although it could also effectively convert HMF (entry 3, Table 2). This comparison illustrates the advantage of in situ-encapsulated Pt NPs for the present transformation. Furthermore, the 0.5\%Pt@Beta (entry 4, Table 2) showed a similar activity to that of $0.2 \% \mathrm{Pt} / \mathrm{Beta}$, which was attributable to the inferior encapsulation of Pt NPs, as demonstrated by the XPS results. To confirm this hypothesis, 0.2\%Pt@Beta was post-treated with an aqueous $\mathrm{NaOH}$ solution to partly expose the Pt NPs (Figs. S15-S17). Compared to the parent 0.2\%Pt@Beta, the resultant sample 0.2\%Pt@Beta-OH showed an insignificant Pt content loss (Fig. S18), presenting a considerable conversion (86\%) but dramatically declined selectivity (58\%) (entry 5, Table 2). In parallel, the $0.2 \% \mathrm{Pt} /$ Beta-OH prepared by post-treating $0.2 \% \mathrm{Pt} /$ Beta with an aqueous $\mathrm{NaOH}$ solution showed inferior activity due to the leaching of the $\mathrm{Pt}$ species (Pt content of 0.12 and $0.2 \mathrm{wt} \%$ for $0.2 \% \mathrm{Pt} / \mathrm{Beta}-\mathrm{OH}$ and $0.2 \% \mathrm{Pt} /$ Beta (Fig. S18), implying that the encapsulated Pt NPs had better stability. Notably, with the accompanying successive transformation of HMF into HMFCA, FFCA, and FDCA, the unidentified side product, termed humin, must have formed more or less, which is more severe than the inferior catalyst that is unable to smoothly convert HMF into the target product $[21,24,27]$. Therefore, the selectivity toward either FDCA alone or the overall product decreased when the reaction was catalyzed by the alkali-treated samples of $0.2 \% \mathrm{Pt} @$ Beta-OH and $0.2 \% \mathrm{Pt} / \mathrm{Beta}-\mathrm{OH}$ with low activity, which was attributable to humin formation in such cases. Nevertheless, the conversion of $>99 \%$, although with a low yield of $32 \%$ (entry 7, Table 2) was established over the commercial catalyst $\mathrm{Pt} / \mathrm{C}$, thereby further revealing the efficiency of $0.2 \% \mathrm{Pt} @ B$ Beta.

The key reaction parameters of the base amount, reaction time, reaction temperature, and substrate dosage were investigated in the transformation of HMF into FDCA over $0.2 \%$ Pt@Beta (Table S3). The conversion was 63\% in a base-free system, forming the intermediate products of DFF and FFCA with selectivities of $16 \%$ and $43 \%$ (entry 1, Table S3), respectively, without FDCA detection. The presence of a small amount of $\mathrm{Na}_{2} \mathrm{CO}_{3}$ caused FDCA production via the intermediates of HMFCA and FFCA, and more $\mathrm{Na}_{2} \mathrm{CO}_{3}$ promoted both the conversion of HMF and the oxidation of FFCA into FDCA (entries 2-6, Table S3). A moderate conversion of 76\%, 
Table 2

Oxidation of HMF to FDCA a.

\begin{tabular}{|c|c|c|c|c|c|c|c|}
\hline \multirow{2}{*}{ Entry } & \multirow{2}{*}{ Sample } & \multirow{2}{*}{ Conversion ${ }^{\mathrm{b}}(\%)$} & \multicolumn{3}{|c|}{ Yield c (\%) } & \multirow{2}{*}{ Selectivity d (\%) } & \multirow{2}{*}{ TON e } \\
\hline & & & HMFCA & FFCA & FDCA & & \\
\hline 1 & 0.2\%Pt@Beta & $>99$ & 0 & 0 & 99 & 99 & 97 \\
\hline 2 & Beta & 12 & 5 & 1 & 1 & 8 & - \\
\hline 3 & $0.2 \% \mathrm{Pt} / \mathrm{Beta}$ & 96 & 18 & 34 & 37 & 39 & 36 \\
\hline 4 & 0.5\%Pt@Beta & 97 & 12 & 36 & 44 & 45 & 43 \\
\hline 5 & 0.2\%Pt@Beta-OH & 86 & 15 & 12 & 50 & 58 & 49 \\
\hline 6 & $0.2 \% \mathrm{Pt} /$ Beta- $\mathrm{OH}^{\mathrm{f}}$ & 82 & 12 & 14 & 14 & 17 & 14 \\
\hline 7 & $\mathrm{Pt} / \mathrm{C}$ & $>99$ & 0 & 25 & 32 & 32 & 31 \\
\hline
\end{tabular}

a Reaction conditions: $\mathrm{HMF} 0.1 \mathrm{mmol}$, catalyst $100 \mathrm{mg}, \mathrm{Na}_{2} \mathrm{CO}_{3} / \mathrm{HMF}$ molar ratio $=6$, water $4 \mathrm{~mL}, 90^{\circ} \mathrm{C}, 24 \mathrm{~h}, \mathrm{O}_{2}$ balloon.

${ }^{\mathrm{b}}$ Conversion $=[\mathrm{mol}(\mathrm{HMF}$ converted $)] /[\mathrm{mol}$ (initial HMF) $] \times 100 \%$.

${ }^{c}$ Yield of FDCA $=[\mathrm{mol}(\mathrm{FDCA}$ formed) $] /[\mathrm{mol}$ (initial HMF) $] \times 100 \%$.

d Selectivity of FDCA $=[\mathrm{mol}(\mathrm{FDCA}$ formed $)] /[\mathrm{mol}(\mathrm{HMF}$ converted $)] \times 100 \%$

e TON $=$ [mol (FDCA formed)]/[mol (total Pt atoms)].

${ }_{\mathrm{f}}^{\mathrm{A}}$ fter post-treatment with aqueous $\mathrm{NaOH}$ solution $(0.1 \mathrm{~mol} / \mathrm{L})$.

associated with a low selectivity of $15 \%$, was achieved at a relatively low reaction temperature of $60{ }^{\circ} \mathrm{C}$ (entry 2, Table S3), thereby suggesting that the rate-determining step corresponded to the oxidation of FFCA into FDCA [21]. Fig. 3(A) depicts the kinetic curve of the $0.2 \% \mathrm{Pt} @ B$ Beta-catalyzed reaction, showing the HMF $\rightarrow$ HMFCA $\rightarrow$ FFCA $\rightarrow$ FDCA transformation pathway (Scheme 2). The HMF was rapidly converted in the initial stage, with a relatively high accumulation of FFCA, again suggesting that the oxidation of the second aldehyde oxidation (FFCA $\rightarrow$ FDCA) was involved in the rate-determining step [21]. In addition, a high yield of $90 \%$ with a large TON of 176 (entry 4 , Table S4) was obtained by increasing the substrate concentration and extending the reaction time, thus further reflecting the high efficiency of $0.2 \% \mathrm{Pt} @$ Beta. The catalyst recycling performance was evaluated in a five-run test, thereby demonstrating rare deactivation over 0.2\%Pt@Beta (Figs. 3(B) and S19-21). For comparison, the yield decreased from $37 \%$ over the fresh $0.2 \% \mathrm{Pt} /$ Beta to $23 \%$ in the second run (Fig. S22), which was attributable to Pt leaching, as demonstrated by XRF analysis. Although various heterogeneous catalysts have been explored for the synthesis of FDCA from the oxidation of HMF, many of them still suffer from deactivation during the recycling test or the involvement of high temperature and high $\mathrm{O}_{2}$ pressure to enable smooth conversion [15,16,21,22,43-47]. Compared with those in previous reports, 0.2\%Pt@Beta effectively catalyzed HMF into FDCA under a relatively low temperature and atmospheric pressure, thereby enabling high yield, favorable stability, and large TON, which were superior or at least comparable to the previous efficient ones $[15,16,21]$. Noticeably, a weak base of $\mathrm{Na}_{2} \mathrm{CO}_{3}$ is engaged in the present system to facilitate the conversion under atmospheric $\mathrm{O}_{2}$ conditions, whereas previous base-free systems are usually conducted under high $\mathrm{O}_{2}$ pressure $[15,16,21]$. A comprehensive comparison with the previous efficient Pt-based catalysts in Table S5 additionally reveals the high efficiency of the present catalyst. To the best of our knowledge, 0.2\%Pt@Beta, with regards to the atomically catalytic efficiency of Pt, outperforms all the early Pt catalysts for the oxidation of HMF into FDCA, which is also comparable to that of high-performing Pd and Au catalysts $[15,16,21]$.

\subsection{Understanding catalytic behavior}

The catalytic behavior of heterogeneous noble metal NPs is normally affected by various parameters, including size, dispersion, electronic state, and accessibility $[1,11,48]$. The 0.2\%Pt@Beta, 0.2\%Pt/Beta, and 0.5\%Pt@Beta displayed average Pt NPs size of 5.4, 6.5, and $12 \mathrm{~nm}$, respectively (TEM images). The latter two samples, 0.2\%Pt/Beta and 0.5\%Pt@Beta, showed similar binding energies (XPS analyses), and exhibited inferior activities close to each other (entries 3 and 4, Table 2). Evidently, 0.2\%Pt@Beta with a slightly smaller average particle
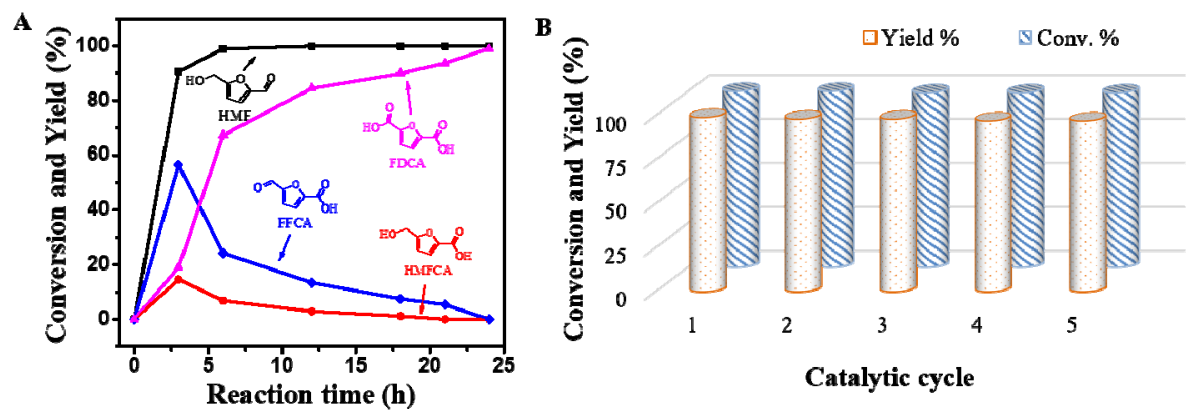

Fig. 3. (A) Kinetic profile and (B) reusability of $0.2 \% \mathrm{Pt} @$ Beta in the oxidation of HMF into FDCA. Reaction conditions: 0.1 mmol HMF, 100 mg catalyst, $\mathrm{Na}_{2} \mathrm{CO}_{3} / \mathrm{HMF}$ molar ratio $=6,4 \mathrm{~mL}$ water, $90^{\circ} \mathrm{C}, 24 \mathrm{~h}$ for (B) $\mathrm{O}_{2}$ balloon. 
size than that of $0.5 \% \mathrm{Pt} @$ Beta exhibited better performance (entry 1, Table 2). These results indicate that the particle size and electronic state cannot significantly affect the activity. The major difference is that the Pt NPs were mainly encapsulated within the $0.2 \% \mathrm{Pt} @$ Beta crystals, whereas the surface Pt NPs were observed for $0.2 \% \mathrm{Pt} /$ Beta and 0.5\%Pt@Beta. Therefore, the enhanced catalytic performance of $0.2 \% \mathrm{Pt} @$ Beta can be tentatively assigned to the encapsulation effect of Pt NPs within the zeolite framework, which is consistent with the inferior activity of the etched $0.2 \% \mathrm{Pt} @$ Beta-OH sample (entry 5, Table 2). Furthermore, the encapsulated Pt NPs enhanced catalytic stability by avoiding leaching-induced deactivation, as demonstrated by the much more stable activity over 0.2\%Pt@Beta relative to $0.2 \% \mathrm{Pt} / \mathrm{Beta}$.

More importantly, such Pt NP encapsulation enables the modulation of the accessibility of reactants and intermediate molecules onto the active sites within the zeolite microchannels via adsorption, as well as product desorption, which may also be associated with the better activity of $0.2 \% \mathrm{Pt} @ B$ Beta. Kinetic analysis revealed the $\mathrm{HMF} \rightarrow \mathrm{HMFCA} \rightarrow$ FFCA $\rightarrow$ FDCA route for the $0.2 \% \mathrm{Pt} @$ Beta-catalyzed oxidation of HMF into FDCA. Thus, to gain further insight, the adsorption capacities of these reactants, intermediates, and products on 0.2\%Pt@Beta were investigated in the absence (neutral) and presence (weak basic) of $\mathrm{Na}_{2} \mathrm{CO}_{3}$ [48-50]. Meanwhile, the affinity of these organic compounds to 0.2\%Pt@Beta colloidal particles was monitored via zeta potential measurement $[51,52]$. In a neutral aqueous solution, HMF was adsorbed on $0.2 \% \mathrm{Pt} @ B$ Bta with a significantly higher capacity ( $\left.66 \mu \mathrm{mol} \mathrm{g}{ }^{-1}\right)$ than HMFCA ( $3 \mu \mathrm{mol}$ $\left.\mathrm{g}^{-1}\right)$, FFCA $\left(7 \mu \mathrm{mol} \mathrm{g}{ }^{-1}\right)$, and FDCA (5 $\left.\mu \mathrm{mol} \mathrm{g}^{-1}\right)$ (Fig. 4(A)), which agreed with the sequence of the zeta potential (Fig. 4(B)). This means that the reactant HMF easily accesses the internal surface of the microchannels to interact with the active sites, whereas the formed FFCA is hard to adsorb and is then converted. Therefore, it exhibits inferiority toward the target product, FDCA, under base-free conditions. Conversely, the affinity of $0.2 \% \mathrm{Pt} @$ Beta toward the two intermediates of HMFCA and FFCA was enhanced in a diluted $\mathrm{Na}_{2} \mathrm{CO}_{3}$ aqueous solution, as demonstrated by the remarkably increased adsorption capacities $\left(3 \rightarrow 22 \mu \mathrm{mol} \mathrm{g}^{-1}\right.$ for HMFCA and $7 \rightarrow 55 \mu \mathrm{mol} \mathrm{g}^{-1}$ for FFCA $)$ and zeta potential values $(-29 \rightarrow-42 \mathrm{mV}$ for HMFCA, $-27 \rightarrow-43 \mathrm{mV}$ for FFCA). This enhancement promotes the effective contact of the intermediates with the active sites, which successively converts into the final product, FDCA. Noticeably, the adsorption capacity of HMF and the corresponding zeta potential increased slightly when the neutral environment changed into a basic one, which, to some extent, also plays a role in accelerating HMF conversion. A similar trend of the adsorption behavior and zeta potential was also observed for $0.2 \% \mathrm{Pt} /$ Beta (Figs. $4(\mathrm{C})$ and S23), thereby further revealing the contribution of the weak base to the transformation of HMF into FDCA. However, the adsorption capacity of FFCA and the zeta potential on $0.2 \% \mathrm{Pt} /$ Beta were lower than those on $0.2 \% \mathrm{Pt} @ B e t a$, indicating responsivity to the lower activity of the former relative to the latter. This influence is further reflected by the adsorption of HMF, HMFCA, FFCA, and FDCA on 0.5\%Pt@Beta and 0.2\%Pt@Beta-OH (Figs. 4(D) and (E)). The conversion of HMF and selectivity towards FDCA was positively related to the adsorption capacities of HMF and FFCA (Fig. $4(F))$.
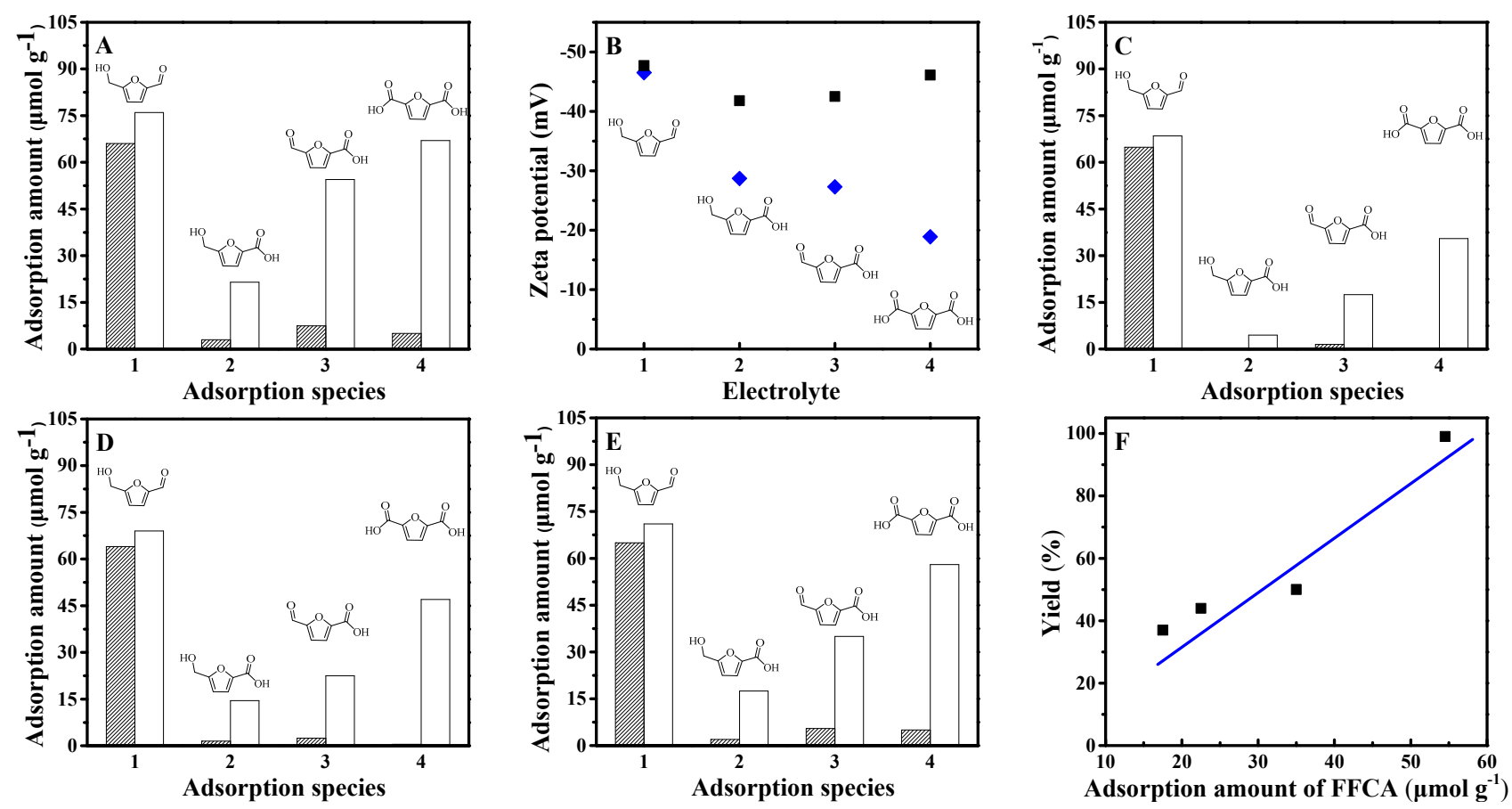

Fig. 4. Adsorption amount of HMF, HMFCA, FFCA, and FDCA on 0.2\%Pt@Beta (A), 0.2\%Pt/Beta (C), 0.5\%Pt@Beta (D), and 0.2\%Pt@Beta-OH (E). Adsorption conditions: $0.01 \mathrm{mmol}$ adsorbate (Diagonal stripe) or $0.01 \mathrm{mmol}$ adsorbate in the presence of $0.06 \mathrm{mmol} \mathrm{Na}_{2} \mathrm{CO}_{3}$ (Blank), $20 \mathrm{mg}$ $0.2 \% \mathrm{Pt} @ B$ Beta, $1 \mathrm{~mL}$ water, room temperature, $24 \mathrm{~h}$. (B) Zeta potentials of $0.2 \% \mathrm{Pt} @$ Beta colloidal particles from an emulsion with an aqueous solution of adsorbate $(1 \mathrm{mmol} \mathrm{L}-1)$ (Blue diamond) or an aqueous solution of adsorbate $\left(1 \mathrm{mmol} \mathrm{L}^{-1}\right)$ in the presence of $\mathrm{Na}_{2} \mathrm{CO}_{3}\left(6 \mathrm{mmol} \mathrm{L}^{-1}\right)(\mathrm{Black}$ square). (F) The changing trend of the yield with the adsorption amount of FFCA. 
Generally, the intrinsic benefits of encapsulating noble metal NPs are associated with their location within zeolite crystals, including the combined advantages of stabilized noble metal NPs, regular microporous channels, and internal properties of zeolites, such as tunable acid/base sites, high ther$\mathrm{mal} /$ hydrothermal stability, variable structures, and chemical compositions $[10,13,27,29,31,53]$. In this work, the advantageous encapsulation effects of Pt@Beta embody not only stability enhancement but also activity and selectivity strengthening. Comprehensively, the encapsulation of Pt NPs within BEA crystals allows favorable kinetic stabilization over the thermodynamically unstable Pt NPs by providing electrostatic interaction and rigid physical shelling of the zeolite skeleton $[10,13]$. The deactivation due to $\mathrm{Pt}$ leaching during the reaction usually causes low activity, while the zeolite matrix-stabilized Pt NPs can evince superior activity by preventing Pt leaching, as demonstrated by the activity comparison in Table 2. Moreover, because of the location of Pt active species crossing several microchannels of zeolite crystals, the diffusion, adsorption, and desorption of the reactant, intermediate, and product are closely related to the zeolitic pore configuration (size, shape, surface states, etc.), and thus significantly affect the selectivity and activity in many cases [53,54]. For the 0.2\%Pt@Beta-catalyzed HMF oxidation into FDCA, the affinity toward the reaction intermediate of FFCA is enhanced due to molecular recognition, thereby leading to enhanced activity and selectivity for the entire oxidation process.

\section{Conclusions}

The direct synthesis of Pt@Beta zeolite was achieved using a hydrothermal approach involving an unusual acid-cohydrolysis pretreatment, wherein the ligand, MPTS was used to promote the in situ encapsulation of Pt NPs. The addition stage of the Pt precursor and the type and amount of ligand play a vital role in zeolite formation and Pt NP incorporation. The Pt NPs of the 0.2\%Pt@Beta were encapsulated mostly within the beta crystals; thus, enhancing the stability of the $\mathrm{Pt}$
NPs. Consequently, the 0.2\%Pt@Beta offered a high yield, TON, and good stability in the oxidation of HMF into FDCA. Systematic comparisons, including the postimpregnated Pt NPs on beta zeolite, suggest that the enhanced catalytic reusability arises from the protection of the robust zeolite skeleton against the potential leaching of Pt active sites during the reaction. More interestingly, the resulting encapsulation effect promotes the adsorption of the intermediate FFCA, which accelerates the further oxidation of FFCA into FDCA, as well as the rate-determining step in the transformation of HMF into FDCA under applied reaction conditions. This work presents an efficient Pt-based catalyst for the synthesis of FDCA from HMF and also highlights the potential of encapsulated noble metal NPs within zeolite crystals toward atom efficiency and stable heterogeneous catalysts.

\section{Electronic supporting information}

Supporting information is available in the online version of this article.

\section{References}

[1] R. Poupart, D. Grande, B. Carbonnier, B. Le Droumaguet, Progr. Polym. Sci., 2019, 96, 21-42.

[2] M. R. Axet, K. Philippot, Chem. Rev., 2020, 120, 1085-1145.

[3] T. S. Rodrigues, A. G. M. da Silva, P. H. C. Camargo, J. Mater. Chem. A, 2019, 7, 5857-5874.

[4] J. Feng, C. Gao, Y. Yin, Nanoscale, 2018, 10, 20492-20504.

[5] R. W. Lord, C. F. Holder, J. L. Fenton, R. E. Schaak, Chem. Mater., 2019, 31, 4605-4613.

[6] L. Wang, L. Wang, X. Meng, F.-S. Xiao, Adv. Mater., 2019, 31, 1901905.

[7] A. Aitbekova, C. J. Wrasman, A. R. Riscoe, L. Y. Kunz, M. Cargnello, Chin. J. Catal., 2020, 41, 998-1005.

[8] J. Zhang, L. Wang, B. Zhang, H. Zhao, U. Kolb, Y. Zhu, L. Liu, Y. Han, G. Wang, C. Wang, D. S. Su, B. C. Gates, F.-S. Xiao, Nat. Catal., 2018, 1, 540-546.

[9] J. Xu, Q. Wang, F. Deng, Acc. Chem. Res., 2019, 52, 2179-2189.

\section{Graphical Abstract}

Chin. J. Catal., 2021, 42: 994-1003 doi: 10.1016/S1872-2067(20)63720-2

\section{Straightforward synthesis of beta zeolite encapsulated Pt nanoparticles for the transformation of 5-hydroxymethyl furfural into 2,5-furandicarboxylic acid}

Xiaoling Liu, Lei Chen, Hongzhong Xu, Shi Jiang, Yu Zhou *, Jun Wang * Nanjing Tech University

Beta zeolite-encapsulated Pt NPs provided a high yield and turnover number in the oxidation of HMF into FDCA with atmospheric $\mathrm{O}_{2}$.

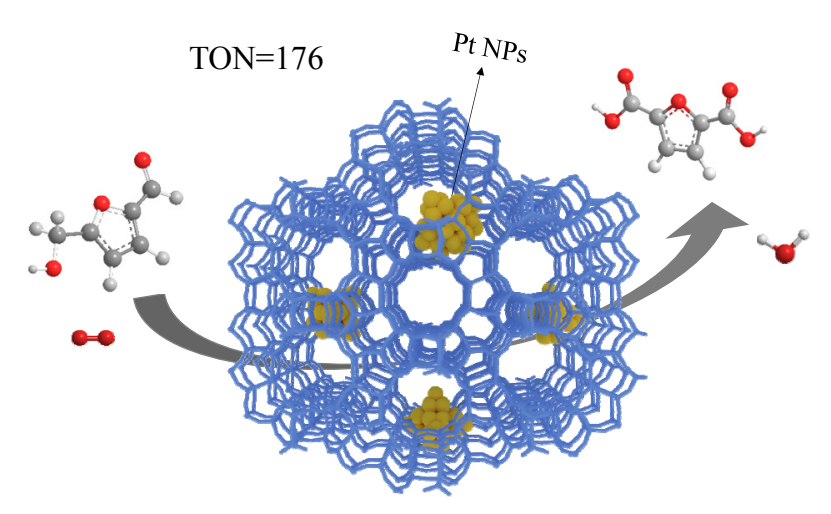


[10] L. Wang, S. Xu, S. He, F.-S. Xiao, Nano Today, 2018, 20, 74-83.

[11] Y. Chai, W. Shang, W. Li, G. Wu, W. Dai, N. Guan, L. Li, Adv. Sci., 2019, 6, 1900299.

[12] H. J. Cho, D. Kim, J. Li, D. Su, B. Xu, J. Am. Chem. Soc., 2018, 140, 13514-13520.

[13] S. Wu, X. Yang, C. Janiak, Angew. Chem., Int. Ed., 2019, 58, 12340-12354.

[14] Y. Wang, W. Deng, B. Wang, Q. Zhang, X. Wan, Z. Tang, Y. Wang, C. Zhu, Z. Cao, G. Wang, H. Wan, Nat. Commun., 2013, 4, 2141.

[15] Y. Wang, S. De, N. Yan, Chem. Commun., 2016, 52, 6210-6224.

[16] L. Hu, A. He, X. Liu, J. Xia, J. Xu, S. Zhou, J. Xu, ACS Sustainable Chem. Eng., 2018, 6, 15915-15935.

[17] Z. Chen, Y. Xiao, C. Zhang, Z. Fu, T. Huang, Q. Li, Y. Yao, S. Xu, X. Pan, W. Luo, C. Li, Chin. J. Catal., 2020, 41, 698-709.

[18] X. Cao, H. Liu, J. Wei, X. Tang, X. Zeng, Y. Sun, T. Lei, G. Zhao, L. Lin, Chin. J. Catal., 2019, 40, 192-203.

[19] Y. Jing, Y. Xin, Y. Guo, X. Liu, Y. Wang, Chin. J. Catal., 2019, 40, 1168-1177.

[20] H. Xia, S. Xu, H. Hu, J. An, C. Li, RSC adv., 2018, 8, 30875-30886.

[21] M. Sajid, X. Zhao, D. Liu, Green Chem., 2018, 20, 5427-5453.

[22] F. Liguori, P. Barbaro, N. Calisi, ChemSusChem, 2019, 12, 2558-2563.

[23] Y. Shan, Z. Sui, Y. Zhu, J. Zhou, X. Zhou, D. Chen, Angew. Chem. Int. Ed., 2018, 57, 9770-9774.

[24] M. Kim, Y. Su, A. Fukuoka, E. Hensen, K. Nakajima, Angew. Chem. Int. Ed., 2018, 57, 8235-8239.

[25] Z. Zhang, J. Zhen, B. Liu, K. Lv, K. Deng, Green Chem., 2015, 17, 1308-1317

[26] S. Siankevich, G. Savoglidis, Z. Fei, G. Laurenczy, D. T. L. Alexander, N. Yan, P. J. Dyson, J. Catal., 2014, 315, 67-74.

[27] W. Zhuang, X. Liu, L. Chen, P. Liu, H. Wen, Y. Zhou, J. Wang, Green Chem., 2020, 22, 4199-4209.

[28] H. P. Winoto, Z. A. Fikri, J.-M. Ha, Y.-K. Park, H. Lee, D. J. Suh, J. Jae, Appl. Catal. B, 2019, 241, 588-597.

[29] M. Moliner, J. E. Gabay, C. E. Kliewer, R. T. Carr, J. Guzman, G. L. Casty, P. Serna, A. Corma, J. Am. Chem. Soc., 2016, 138, 15743-15750.

[30] D. Gao, A. Zheng, X. Zhang, H. Sun, X. Dai, Y. Yang, H. Wang, Y. Qin, S. Xu, A. Duan, Nanoscale, 2015, 7, 10918-10924.

[31] T. Otto, S. I. Zones, E. Iglesia, J. Catal., 2016, 339, 195-208.

[32] Y. Chai, S. Liu, Z.-J. Zhao, J. Gong, W. Dai, G. Wu, N. Guan, L. Li, ACS Catal., 2018, 8, 8578-8589.

[33] J. Xie, W. Zhuang, N. Yan, Y. Du, S. Xi, W. Zhang, J. Tang, Y. Zhou, J. Wang, Chem. Eng. J., 2017, 328, 1031-1042.
[34] W. Zhang, W. Hou, T. Meng, W. Zhuang, J. Xie, Y. Zhou, J. Wang, Catal. Sci. Technol., 2017, 7, 6050-6058.

[35] W. B. Widayatno, G. Guan, J. Rizkiana, J. Yang, X. Hao, A. Tsutsumi, A. Abudula, Appl. Catal. B, 2016, 186, 166-172.

[36] X. Tian, X. Zhao, Y. Su, L. Wang, H. Wang, D. Dang, B. Chi, H. Liu, E. J. M. Hensen, X. Liu, B. Y. Xia, Science, 2019, 366, 850-856.

[37] X. K. Wan, H. B. Wu, B. Y. Guan, D. Luan, X. W. D. Lou, Adv. Mater., 2020, 32, 1901349.

[38] Á. Cantín, A. Corma, M. J. Díaz-Cabañas, J. L. Jordá, M. Moliner, F. Rey, Angew. Chem. Int. Ed., 2006, 118, 8181-8183.

[39] A. B. Pinar, L. Gómez-Hortigüela, L. B. McCusker, J. Pérez-Pariente, Chem. Mater., 2013, 25, 3654-3661.

[40] W. Fu, Z. Yuan, S. Jin, W. Liu, Z. Wang, C. Wang, Y. Wang, W. Yang, M.-Y. He, Chin. J. Catal., 2019, 40, 856-866.

[41] S. L. Bergman, J. Granestrand, Y. Tang, R. S. París, M. Nilsson, F. F. Tao, C. Tang, S. J. Pennycook, L. J. Pettersson, S. L. Bernasek, Appl. Catal. $B, 2018,220,506-511$.

[42] A. J. Therrien, A. J. R. Hensley, M. D. Marcinkowski, R. Zhang, F. R. Lucci, B. Coughlin, A. C. Schilling, J.-S. McEwen, E. C. H. Sykes, Nat. Catal., 2018, 1, 192-198.

[43] Y.-T. Liao, V. C. Nguyen, N. Ishiguro, A. P. Young, C.-K. Tsung, K. C. W. Wu, Appl. Catal. B, 2020, 270, 118805.

[44] A. I. M. Rabee, S. D. Le, K. Higashimine, S. Nishimura, ACS Sustainable Chem. Eng., 2020, 8, 7150-7161.

[45] J. Yang, H. Yu, Y. Wang, F. Qi, H. Liu, L.-L. Lou, K. Yu, W. Zhou, S. Liu, Catal. Sci. Technol., 2019, 9, 6659-6668.

[46] D. K. Mishra, H. J. Lee, J. Kim, H.-S. Lee, J. K. Cho, Y.-W. Suh, Y. Yi, Y. J. Kim, Green Chem., 2017, 19, 1619-1623.

[47] T. Gao, J. Chen, W. Fang, Q. Cao, W. Su, F. Dumeignil, J. Catal., 2018, 368, 53-68.

[48] J. Zhang, L. Wang, Y. Shao, Y. Wang, B. C. Gates, F.-S. Xiao, Angew. Chem. Int. Ed., 2017, 56, 9747-9751.

[49] K. Z. Elwakeel, A. A. El-Bindary, E. Y. Kouta, E. Guibal, Chem. Eng. J., 2018, 332, 727-736.

[50] J. Wang, Y. Li, Z. Lv, Y. Xie, J. Shu, A. Alsaedi, T. Hayat, C. Chen, J. Colloid Interfaces Sci., 2019, 542, 410-420.

[51] X. Liu, P. Maki-Arvela, A. Aho, Z. Vajglova, V. M. Gun'ko, I. Heinmaa, N. Kumar, K. Eranen, T. Salmi, D. Y. Murzin, Molecules, 2018, 23, 946.

[52] Q. Wang, W. Hou, S. Li, J. Xie, J. Li, Y. Zhou, J. Wang, Green Chem., 2017, 19, 3820-3830.

[53] C. Wang, L. Wang, J. Zhang, H. Wang, J. P. Lewis, F.-S. Xiao, J. Am. Chem. Soc., 2016, 138, 7880-7883.

[54] J. Tang, P. Liu, X. Liu, L. Chen, H. Wen, Y. Zhou, J. Wang, ACS Appl. Mater. Interfaces, 2020, 12, 11522-11532.

\title{
直接合成Beta沸石封装Pt纳米粒子用于5-羟甲基糠醛合成2,5-呋喃二甲酸
}

\author{
刘晓玲, 陈磊, 许红中, 蒋 师, 周 瑜 ${ }^{*}$, 王 军 \\ 南京工业大学化工学院, 材料化学国家重点实验室, 江苏南京210009
}

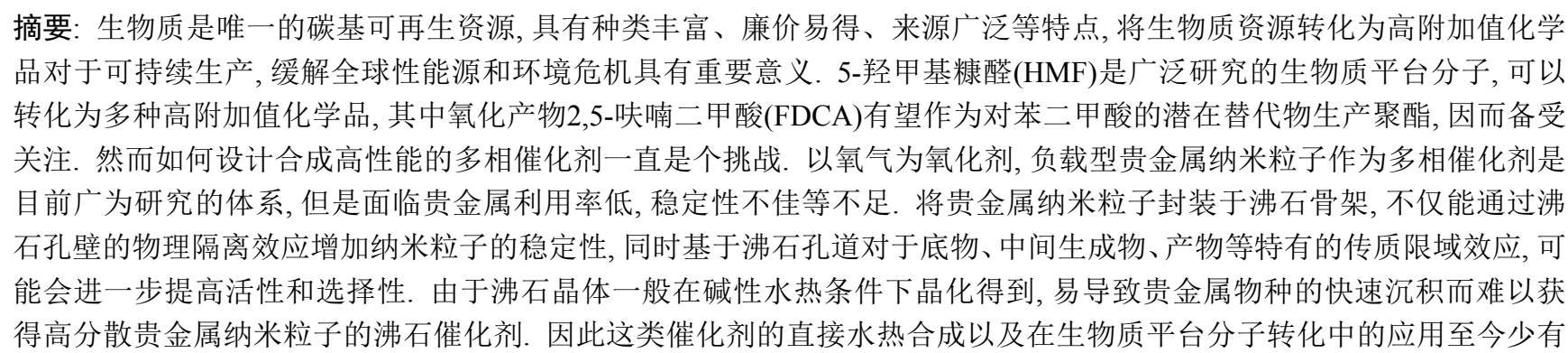


报道. 本文设计合成了一种封装铂 $(\mathrm{Pt})$ 纳米粒子的Beta沸石 $(\mathrm{Pt} @ \mathrm{Beta})$, 应用于催化HMF合成FDCA的反应, 以常压氧气为氧 源, 水作为溶剂, 获得了高活性和稳定性以及极高的Pt原子利用率.

我们采用一种不同以往的酸水解路径合成Pt@Beta沸石. 首先将Pt前驱体、硅源(正硅酸四乙酯)和有机配体(3-颈丙基 甲氧基硅氧烷)在弱酸性条件下水解缩合, 增强了硅物种与 Pt物种的相互作用, 有效避免了贵金属氢氧化物的形成, 这种特 殊的预水解缩合环节有效促进了后续碱性环境水热合成中的Pt物种进入沸石晶内的过程, 最终形成较为稳定和均匀分散 的Pt纳米粒子. 系统考察了配体种类、配体用量、配体加料顺序等合成条件对于催化剂制备的影响规律, 获得了高分散 $\mathrm{Pt}$ 纳米粒子的适宜合成条件, 结果表明, 在酸水解过程中加入适量的有机配体, 对于最终催化剂中Pt的高度分散至关重要. 将 不同Pt含量的Pt@Beta和后负载方法制备的Pt/Beta进行细致对比, XPS和TEM表征结果发现, 只有直接水热合成法能够将Pt 较好地封装在沸石晶体内. 封装较低含量Pt的样品 $(0.2 \% \mathrm{Pt} @ \mathrm{Beta})$ 在HMF氧化制FDCA反应中表现出高的收率和良好的复 用稳定性. 为探究其高活性缘由, 测试了不同催化剂对底物、中间体以及产物的吸附性能, 结果表明, $0.2 \% \mathrm{Pt} @ \mathrm{Beta}$ 对于中 间体2-甲酰呋喃甲酸(FFCA)吸附能力较强, 能有效加速FFCA到FDCA这一决速步的反应, 从而促进了FDCA的生成. 此外, $0.2 \% \mathrm{Pt} @ B$ Bta中贵金属物种位于沸石晶内, 得益于沸石刚性无机骨架的稳定化作用, 该催化剂能有效阻止Pt纳米粒子在苛 刻条件下的聚集, 避免液固相反应体系中的溶脱流失, 从而表现出优良的催化复用稳定性.

关键词: 水热合成; 沸石; 贵金属纳米粒子; 多相催化; 生物质转化

收稿日期: 2020-07-18. 接受日期: 2020-08-31. 上网日期: 2020-11-22.

*通讯联系人. 电话/传真: (025)58139803; 电子邮箱: njutzhouyu@njtech.edu.cn

\#通讯联系人. 电子邮箱: junwang@njtech.edu.cn

基金来源：国家自然科学基金(22072065, U1662107, 21476109, 21303084); 江苏省“六大人才高峰”项目(JNHB-035); 江苏省自然 科学青年基金(SBK2020044703); 江苏省高等学校优势学科项目(PAPD).

本文的电子版全文由Elsevier出版社在ScienceDirect上出版(http://www.sciencedirect.com/science/journal/18722067). 